\title{
Macrophages to Non-Squamous Epithelial Cells Ratio Measurement
}

National Cancer Institute

\section{Source}

National Cancer Institute. Macrophages to Non-Squamous Epithelial Cells Ratio

Measurement. NCI Thesaurus. Code C135431.

The determination of the ratio of macrophages compared to non-squamous epithelial cells present in a sample. The measurement may be expressed as a ratio or percentage. 